\title{
Effectiveness of Psychosocial Supportive Care Trial on Quality of Life among Breast Cancer Patients: An Interventional Study at the National Cancer Institute, Egypt
}

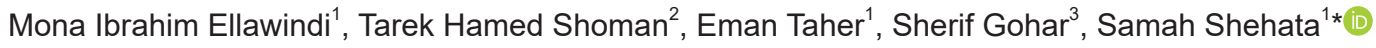 \\ ${ }^{1}$ Department of Public Health, Faculty of Medicine, Cairo University, Giza, Egypt; ${ }^{2}$ Department Radiation Oncology, National \\ Cancer Institute, Cairo University, Giza, Egypt; ${ }^{3}$ Department of Psychiatry, Faculty of Medicine, Cairo University, Giza, Egypt
}

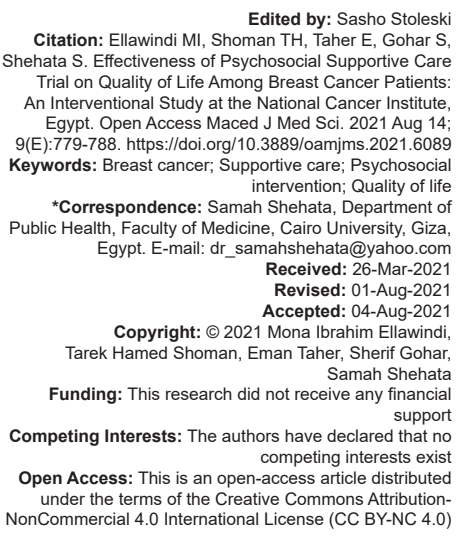

\section{Abstract}

BACKGROUND: Breast cancer (BC) patients suffer from many psychosocial problems due to their health condition and treatment side effects so they are in great need for psychosocial supportive care.

AIM: The aim of the study was to provide a comprehensive psych-social supportive health-care model for BC patients a step toward improving their quality of life (QOL).

PATIENTS AND METHODS: Random assignment was done for 185 patients with primary operated BC to a contro or an intervention group. The researcher offered five daily successive psychosocial supportive care sessions for the patients in the intervention group. All patients were followed up for coping ability, mood and QOL 8 weeks after the intervention.

RESULTS: The intervention had statistically significant effects on psychological distress, depression, problem focused, and active emotional coping domain, while had not any statistically significant effects on avoidant emotional coping domain.

CONCLUSION: Psychosocial supportive developed health-care model decreased psychological distress, depression, and improved QOL among patients with primary BC.

\section{Introduction}

Breast cancer $(B C)$ was the third highest incident cancer in 2017, with an estimated 1,960,681 incident cases and a high prevalence in females. BC is the leading cause of cancer death in females and also a non-negligible cause of cancer death in males worldwide, claiming 181,004 lives and resulting in 17.7 million disability-adjusted life years, making it one of the most severe burdensome cancer globally [1].

One of the most stressful events that can happen in one's life is being diagnosed with cancer, having cancer inevitably result in serious long-term psychosocial impairments [2]. Depression and anxiety are very common among people diagnosed with cancer; stress is often a trigger for anxiety and depression [3].

Women with $\mathrm{BC}$ experience a wide range of emotional and functional impairments, after mastectomy, such as depression, and these impairments have intense psychosocial effects, many studies have demonstrated that the prevalence of depression after mastectomy ranges from $1 \%$ to $56 \%$ [4].
Surgery, fear of recurrence, co adjuvant therapy, bodily changes, reduced femininity, and sexuality are factors associated with the triggering of psychosocial and physical stress in BC patients [5].

Women with newly diagnosed BC often experience post-traumatic stress disorder syndrome (PTSD) symptoms [6]; a patient diagnosed with PTSD is at a great risk for suicide and intentional self-harm [7].

Suicide is very frequent among patients with cancer [8], risk factors that could likely increase attempts of suicide include; uncontrollable pain, untreated depression, lack of social support, substance use, family history of suicide, and deprivation [9].

Cancer patients have poor quality of life (QOL) because of sleep difficulty, excessive worries regarding survival and depressive mood [10], additionally QOL is impaired by the nutritional status as cancer leads to a deterioration of the patients' nutritional status [11]. Wide varieties of psychosocial interventions have been developed to deal with mood symptoms in cancer patients since the 1980s [12]. 
These psychological interventions are inexpensive ways to alleviate the psychological distress [13] and possibly to improve the function of the immune system [14]. Based on a systematic review for psycho-social interventions, it was found that relaxation techniques, psycho-educational therapy, individual, and group psychotherapy were very effective with a high level of evidence in terms of reducing anxiety, depression, and improving QOL [15].

Socio-cognitive therapy based interventions in cancer patients resulted in improvements in depression, social outcomes, objective physical outcomes, and specific QOL outcomes [16]. Relaxation technique is a commonly used effective, efficient, and inexpensive method to change the mental processes and behavior of the individual [17], [18], for cancer patients, relaxation training, have positive effects on anxiety, due to the difficulties of the disease and the side effects of chemotherapy administered [18], [19].

Relaxation therapy is recommended, as an effective care program in patients with $B C$ as it is effective in the improvement of depression, anxiety, and stress [20]. The objectives of this study were to assess psycho-social problems recruited from cancer patients, design a program tailored according to the results obtained from the preliminary situations analysis and reduce suffering, psychological distress and improve coping appear to improve general well-being for the recipients of this trial.

\section{Methods}

All methods used in this study were carried out in accordance with relevant guidelines and regulations. The study protocol and the formats used in data collection were revised and approved by ethical committee of Kasr Al-Aini Faculty of Medicine.

\section{Study design and setting}

This study was a quasi-experiment; this type of study was used to evaluate interventions but did not use randomization. Like randomized trials, quasi experiments aim to demonstrate causality between an intervention and an outcome, it was performed with pretest and post-test, control and a follow-up; this study was performed at the radiation oncology department in the National Cancer Institute ( $\mathrm{NCl})$.

$\mathrm{NCl}$ was selected because it is specialized cancer center with high rate of flow of patients; the average number of patients attending the radiotherapy sessions is about 200-220 patients every day.

\section{Study population}

The statistical population consisted of women with primary $\mathrm{BC}, 185$ women were chosen; they were divided into two groups, the experimental group (90) subjected to psychosocial developed health-care model intervention while the control group (95) did not undergo any intervention.

\section{Sampling technique}

Between October 1, 2016, and May 1, 2017, a sample of $185 \mathrm{BC}$ patients with Stages I-III primary operated $\mathrm{BC}$ treated at the $\mathrm{NCl}$ who fulfilled the eligibility criteria throughout data collection period were included as shown in Figure 1. After explaining to the participants, the steps of the study and its objectives the participants who agreed to join the study signed an informed consent form before enrollment in the study, they completed a baseline questionnaire, and the researcher then divided them to intervention or control group in the following way.

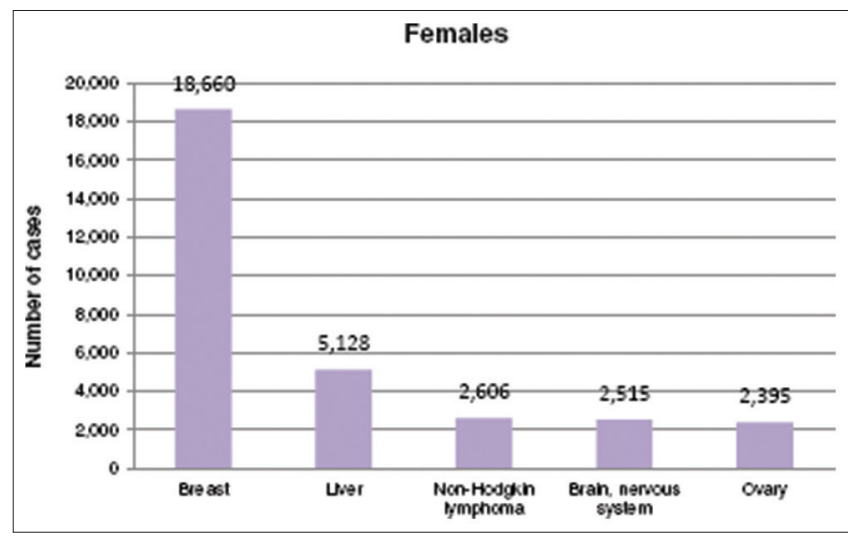

Figure 1: Number of cases of different cancer types in Egyptian female (WHO, 2014)

Recruitment of control group was done in the second or third period (from 1 to 3 p.m., from 4 to 7 p.m., respectively), recruitment of intervention group done in the first period (from 9 a.m.to 12 p.m.)

This design was chosen because of the very high likelihood of significant contamination (i.e., exchange of information between intervention group and control group) if patients who were receiving care in the same setting. Of the 250 patients who were interviewed, $210(84 \%)$ agreed to participate, 20 (8\%) not met the inclusion criteria, and $20(8 \%)$ refused as they did not have time or they felt they had no need for support.

210 subjects were enrolled and consented to take part in the study (control $=110$ and intervention $=100$ ), from the intervention group five were dropped out because they changed their opinions about participating in the trial after they had completed the baseline questionnaire, another five patients were lost for follow-up. As regard the control group, five patients 
were dropped out, another ten patients were lost for follow-up (Figure 2).

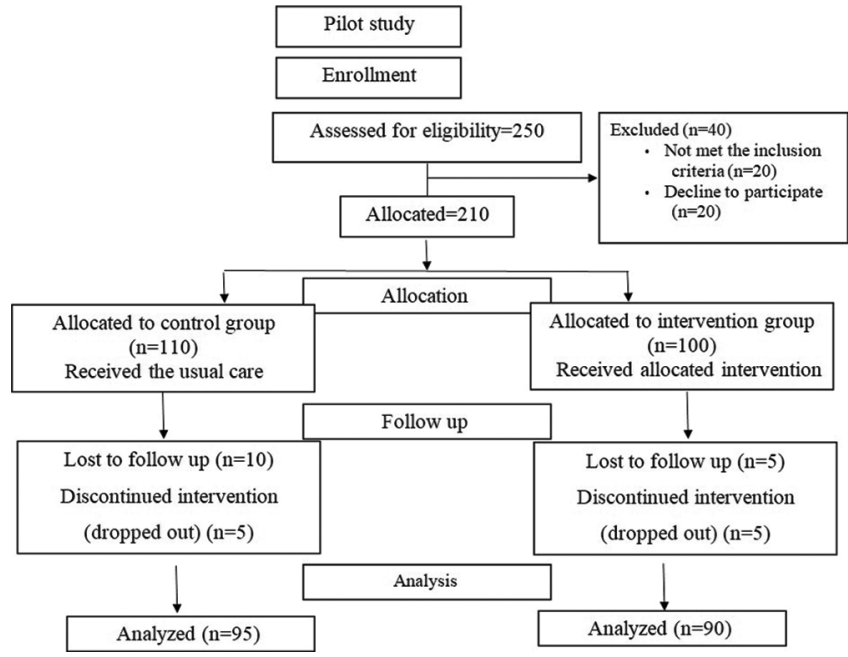

Figure 2: Subject flow diagram

\section{The intervention group}

Subjects assigned to the intervention group received the current standard radiation therapy provided in $\mathrm{NCl}$, in addition, they received five psychosocial supportive care sessions for 4-5 successive days after the first interview and each session lasted for 20-30 min for each group of patients. At the end of each session, the researcher summarized the main messages and answered patient inquiries.

\section{The control group}

Subjects assigned to the control group received the current standard radiation therapy provided in $\mathrm{NCl}$, without specific intervention. If patients had questions concerning nutrition, mood changes they were advised by the $\mathrm{NCl}$ attending physician or the nurses but not the researcher.

\section{Sample size}

We planned a study of matched sets of patients receiving the experimental and control treatments with one matched control(s) per experimental subject. Prior data indicated that the probability of a treatment failure among controls is 0.5 and the correlation coefficient for exposure between matched experimental subjects is 0.3 . If the true odds ratio for failure in control subject's relative to experimental control subjects is 3 , we needed to study 88 experimental subjects with 1 matched control(s) per experimental subject to be able to reject the null hypothesis that this odds ratio equals 1 with probability (power) 0.8 . The Type I error probability associated with this test of this null hypothesis is 0.05 , If we would guard against the dropout rate of $30 \%$ we might think of around 120 for each arm.

\section{Measures}

The design included baseline and one follow-up assessment, at 8 weeks after the intervention.

\section{Psychological distress}

12 items General Health Questionnaire (GHQ), which is a measure of current mental health, evaluated the psychological distress level of the sample and since its development by Goldberg and Blackwell in the 1970s; it has been extensively used in different settings and different cultures [21].

Each item of the questionnaire is rated on a fourpoint scale (less than usual, no more than usual, rather more than usual, or much more than usual); and, for example, when using the GHQ-12 it gives a total score of 36 or 12 based on the selected scoring methods. The most common scoring methods are bi-modal (0-0-1-1) and Likert scoring styles (0-1-2-3). In this study, we chose the GHQ scoring style (0-0-1-1) over the Likert scoring styles (0-1-2-3), as this scoring style helped to eliminate any biases, which may originate from the participants who chose responses 1 and 4 or 2 and 3 [22].

The scores were calculated by summing up all the items together on the scale ranging from 0 to 12 , to determine the level of psychological well-being, the cutoff point 6 was used, the maximum score for any individual study participant is therefore 12 . Score $<6$ indicate no evidence of probable mental ill health, score 6 and more indicates probable psychological disturbance or mental ill health, a validated Arabic version of $\mathrm{GHQ}$ was used [23].

\section{Depression}

It was assessed by Hamilton Depression Rating Scale (HRSD), it is a 17 item semi structured interview designed to measure symptom severity in depressed patients [24]. Each question of the 17 items has between 3 and 5 possible responses which increase in severity. A score of $0-7$ is considered to be normal, scores of 20 or higher indicate moderately severe depression.

0-7 = Normal, 8-13 = Mild Depression, 14-18 = Moderate Depression, $19-22=$ Severe Depression, and $>23=$ Very Severe Depression.

Analysis of full score as well as subscales was done to indicate that the patient is euthymic with a cutoff score of $\leq 7$, which is considered euthymic, and to assess the residual depressive symptoms and the sleep disturbance. Items such as depressed mood, suicidal thoughts, and guilt feelings items were used to assess the residual depressive symptoms, and insomnia items were used to assess the sleep disturbance. A validated Arabic version of HRSD was used [25]. 


\section{Coping}

The coping behaviors and thoughts were assessed by Brief COPE scale (validated short form of the COPE inventory); it is a self-report questionnaire formed of 14 dimensions every dimension has two items. The four-point Likert scale, ranging from “I haven't been doing this at all" (score one) to "I have been doing this a lot" (score four) rated each item. There were no cutoff point scores for coping strategies in this study [26], [27].

The 14 dimension are self-distraction, active coping, denial, substance use, use of emotional support, use of instrumental support, behavioral disengagement, venting, positive reframing, planning, humor, acceptance, religion, and self-blame, a validated brief coping scale was used [28].

The 14 subscales were grouped into three coping categories by summing items accordingly (with higher scores indicating greater intensity of use of the coping strategy). The three coping strategies and their associated subscales were: A-problem-focused coping (adaptive mode of coping) it includes active coping, planning, instrumental support, and religion scales.

B-active emotional coping (adaptive emotionregulation strategy) it includes venting, positive reframing, humor, acceptance, and emotional support scales. C-avoidant emotional coping (viewed as maladaptive) it includes self-distraction, denial, behavioral disengagement, self-blame, and substance use [29].

\section{Demographic information}

Information related to women's marital status, educational status, and occupation was obtained. Some information (age, time since diagnosis, and stage of disease) was obtained during an individual interview with the participant.

Table 1: Baseline socio-demographic characteristics

\begin{tabular}{|c|c|c|c|}
\hline Variable & Control group $(n=95)$ & Intervention group $(\mathrm{n}=90)$ & $\mathrm{p}$-value \\
\hline \multicolumn{4}{|l|}{ Age in year } \\
\hline Mean \pm SD & $48.7 \pm 13.2$ & $47.9 \pm 11.9$ & \multirow[t]{3}{*}{0.68} \\
\hline Median (IQR) & $49.00(38: 60)$ & $47(38: 57)$ & \\
\hline Variable & $\mathrm{n}(\%)$ & $n(\%)$ & \\
\hline \multicolumn{4}{|l|}{ Marital status } \\
\hline Married & $58(61.1)$ & $58(64.6)$ & \multirow[t]{4}{*}{0.74} \\
\hline Widow & $21(22.1)$ & $19(21.1)$ & \\
\hline Divorced & $11(11.6)$ & $11(12.2)$ & \\
\hline Non married & $5(5.3)$ & $2(2.2)$ & \\
\hline \multicolumn{4}{|l|}{ Education } \\
\hline Preparatory or less & $41(43.2)$ & $44(48.9)$ & \multirow[t]{3}{*}{0.63} \\
\hline High school or equal & $36(37.9)$ & $27(30)$ & \\
\hline University/Postgraduate & 18 (18.9) & $19(21.1)$ & \\
\hline \multicolumn{4}{|l|}{ Occupation } \\
\hline Employed & $1(1.1)$ & $1(1.1)$ & \multirow[t]{4}{*}{0.76} \\
\hline Retired & $2(2.1)$ & $1(1.1)$ & \\
\hline Disabled & $31(32.6)$ & $24(26.7)$ & \\
\hline Never employed & $61(64.2)$ & $64(71.1)$ & \\
\hline
\end{tabular}

\section{Intervention}

- Radiation therapy sessions provided to BC patient from Saturday to Wednesday. Patients start registration at the radiation oncology department at $7.30 \mathrm{am}$. Technicians started their work at 9 am up to $7 \mathrm{pm}$ divided into three periods from 9 am to $12 \mathrm{pm}$, from $1 \mathrm{pm}$ to $4 \mathrm{pm}$ and from $4 \mathrm{pm}$ to $7 \mathrm{pm}$

- $\quad$ In the first period from 9 am to $12 \mathrm{pm}$ about 5 to 6 patients were interviewed and received intervention for 4-5 successive days while in the second or third period About 5 to 6 patients were interviewed as control group interview of each patient took 30-45 min

Interview of each patient took $30-45$ min on the $1^{\text {st }}$ day then average 20-30 min each intervention session for the next days

The interview for data collection was done in the waiting area of the patients after ensuring patient privacy or in private room if available, the initial interview for data collection consumed 30-45 min for each case and each intervention session took average 20-30 min in private room, five sessions of group-based intervention including 6-8 patients was done

Patients' phone numbers (home or cell phone) were taken to help in follow up also researcher's phone number was available for the patients to respond for their inquiries.

The first session focused on nutrition education; it included information on healthy diets and advice about changing the diet if necessary and how to lose or gain weight according to the body mass index.

A brochure was given to intervention group to help remembering information learned from nutritional education session, the brochure was designed by the researcher and revised by two professors from public health and community medicine department and one professor from clinical oncology department; it was developed in simple Arabic language and tested for the literacy level of the study population. Difficult medical terms were simplified.

The second session was about regular deep breathing exercise as a relaxation technique, the researcher explained to the patients the importance of the regular deep breathing and illustrated its steps, and a flyer was given to intervention group to help remembering information learned from this session.

The last three sessions were about stress management, problem solving, coping and cognitive reframing to examine and deal with negative thoughts based on cognitive-behavioral theory. The booklet formed of 17 pages; the main outlines and the use of cognitive behavioral therapy (CBT) as the main therapeutic intervention represent a collaborative work between community medicine department, clinical oncology department and psychiatry department. It was designed by the researcher and revised by two professors from public health and community medicine department, one professor from clinical 
oncology department and one lecturer of psychiatry. A booklet was developed in simple Arabic language, pictures and cartoons were used to easily illustrate information and gain attention of the readers.

\section{Statistical analysis}

Quantitative data were examined for normality distribution using the Kolmogorov-Smirnov test and the results were significant $(p<0.05)$ indicating a nonnormal distribution.

The data were summarized using mean and standard deviation (SD) for normally distributed quantitative variables and median and interquartile ranges for not normally distributed quantitative variables, while number and percentage were used to summarize qualitative variables.

Differences in the baseline characteristics of the two groups were compared by the two-sample t-test. Paired t-test and Wilcoxon test were used to test the effect of intervention. Independent sample t-test, Mann-Whitney, and Chi-square tests were used to compare differences between two independent groups.

Spearman Correlation test was used to study the possible impact of coping strategies on depression and psychological health; significant differences were found with level of significance $p<0.05$.

\section{Declarations}

- $\quad$ Ethics approval and consent to participate

An informed written consent was taken from each patient. All data obtained from every patient were confidential and were not used outside the study. The patients have rights to withdraw from the study at any time without giving any reason. All the cost of the investigations was afforded by the researcher.

Our study was approved by Research ethics committee, Faculty of Medicine, Cairo University, on July 15, 2017.

The committee's reference number: N-46-2017

- $\quad$ Consent for publication: Not applicable

- $\quad$ Availability of data and material

The datasets generated and/or analyzed during the current study are not publicly available due to the current Cairo University regulations and Egyptian legislation but are available from the corresponding author on reasonable request and after institutional approval.

- Competing interests
The authors declare that they have no
competing interests.

- $\quad$ Funding
This research received no specific grant from

any funding agency in the public, commercial, or notfor-profit sectors.

\section{Results}

We report the results of the effects of a psychosocial developed health-care model on psychological distress, mood, and coping among females with primary $B C$.

The studied BC patients of the intervention and control groups showed no significant difference as regarding age, marital status, education, and occupation (Table 1).

The results showed that among intervention group there was statistical significant decrease in the mean of psychological distress, as regarding control group there were no statistical significant difference (Table 2).

Table 2: Comparison of psychological health using GHQ of studied patients at baseline and follow-up

\begin{tabular}{|c|c|c|}
\hline Parameters & Control group $(n=95)($ Mean $\pm S D)$ & Intervention group $(\mathrm{n}=90)($ Mean \pm SD) \\
\hline Pre-test & $7.7 \pm 3.5$ & $7.9 \pm 3.4$ \\
\hline Post-test & $7.9 \pm 3.9$ & $3 \pm 4.5$ \\
\hline $\mathrm{p}$-value & 0.48 & $0.00^{*}$ \\
\hline
\end{tabular}
intervention group there was statistical significant decrease in the mean of HRSD, as regarding control group there was no statistical significant difference. Significant at $p \leq 0.05$ (Table 4) showed that among the control group, there were no statistical significant changes except for active emotional coping domain that was significantly increased.

Table 3: Comparison of depression using HRSD of studied patients at baseline and follow-up

\begin{tabular}{lll}
\hline Parameters & Control $(\mathrm{n}=95)$ Mean \pm SD & Intervention $(\mathrm{n}=90)$ Mean $\pm S D$ \\
\hline Pretest & $11.9 \pm 5.8$ & $12.5 \pm 6$ \\
Posttest & $12.6 \pm 6.6$ & $8 \pm 6.8$ \\
$\mathrm{P}$ value & 0.19 & $0.00^{*}$ \\
\hline HRSD: Hamilton Depression Rating Scale.
\end{tabular}

As regarding follow-up of intervention group, the means of the problem-focused, active emotional coping domains significantly increased after 8 weeks of follow-up (intervention group became more adaptive), while there were no significant differences in avoidant emotional coping style subscale.

Table 4: Comparison coping strategies using brief coping scale of studied patients at baseline and follow-up

\begin{tabular}{|c|c|c|c|c|c|c|}
\hline \multirow[t]{2}{*}{ Parameters } & \multicolumn{2}{|c|}{$\begin{array}{l}\text { Control }(n=95) \text { Mean } \\
\pm \text { SD }\end{array}$} & \multirow[t]{2}{*}{$p$-value } & \multicolumn{2}{|c|}{$\begin{array}{l}\text { Intervention }(n=90) \\
\text { Mean } \pm \text { SD }\end{array}$} & \multirow[t]{2}{*}{$p$-value } \\
\hline & Pretest & Posttest & & Pretest & Posttest & \\
\hline Prob & $16.2 \pm 4.4$ & $16.2 \pm 4.2$ & 0.89 & $18 \pm 4.8$ & $22 \pm 5.7$ & $0.00^{*}$ \\
\hline & 01 & $20.9 \pm 4.3$ & 0. & $21.6 \pm 4.5$ & $25 \pm 5.4$ & $0.00^{*}$ \\
\hline Avoidant emotional & $18.5 \pm 3.5$ & $19 \pm 3.6$ & $0.1^{*}$ & $19.7 \pm 4.7$ & $19.1 \pm 3$ & 0.11 \\
\hline
\end{tabular}

As regards the 14 coping subscales, there were no statistical significant changes among the control group except for instrumental support that was significantly decreased and venting that was 
significantly increased. while among intervention group; the behavioral disengagement, self-blame and denial significantly decreased after 8 weeks of follow-up, while acceptance, self-distraction, emotional support, positive reframing, planning, humor, religion, and active coping increased significantly, there were no significant differences in instrumental support, substance use, and venting (Table 5).

Table 6 demonstrates that depression was significantly only negatively correlated with Active coping $\left(r=-0.464^{*}\right)$, religion $\left(r=-0.455^{*}\right)$, planning $\left(r=-0.453^{*}\right)$ and instrumental support $\left(r=-0.351^{*}\right)$ positive reframing $\left(r=-0.315^{*}\right)$, emotional support $(r=$ $\left.-0.328^{*}\right)$, acceptance $\left(r=-0.389^{*}\right)$, and self-distraction $\left(r=-0.436^{*}\right)$ and was significantly positively correlated with behavioral disengagement $\left(r=0.340^{*}\right)$, substance use $\left(r=0.216^{*}\right)$, and self-blame $(r=0.302$ among the intervention group.

Table 5: Comparison coping subscales of studied patients at baseline and follow-up

\begin{tabular}{|c|c|c|c|c|c|c|}
\hline \multirow[t]{2}{*}{ Parameters } & \multicolumn{2}{|c|}{$\begin{array}{l}\text { Control }(n=95) \\
\text { Mean }(S D)\end{array}$} & \multirow[t]{2}{*}{$\mathrm{p}$-value } & \multicolumn{2}{|c|}{$\begin{array}{l}\text { Intervention (n = } \\
\text { 90) Mean (SD) }\end{array}$} & \multirow[t]{2}{*}{$\mathrm{p}$-value } \\
\hline & Pretest & Posttest & & Pretest & Posttest & \\
\hline \multicolumn{7}{|l|}{ A-Problem focused } \\
\hline Active coping & $3.9 \pm 1.5$ & $4.1 \pm 1.7$ & 0.29 & $4.5 \pm 1.6$ & $5.7 \pm 1.8$ & $0.00^{*}$ \\
\hline Religion & $5.1 \pm 1.9$ & $5.1 \pm 1.7$ & 0.86 & $5.1 \pm 2$ & $6.1 \pm 1.9$ & $0.00^{*}$ \\
\hline Planning & $3.4 \pm 1.5$ & $3.6 \pm 1.5$ & 0.18 & $4.2 \pm 2$ & $5.8 \pm 1.8$ & $0.00^{*}$ \\
\hline Instrumental support & $3.6 \pm 1.6$ & $3.3 \pm 1.3$ & $0.04^{*}$ & $4 \pm 1.6$ & $4.3 \pm 1.6$ & 0.09 \\
\hline \multicolumn{7}{|l|}{ B-Active emotional } \\
\hline Venting & $3.8 \pm 1.5$ & $4.4 \pm 1.4$ & $0.00^{*}$ & $4.2 \pm 1.5$ & $4 \pm 1.3$ & 0.07 \\
\hline Positive reframing & $3.8 \pm 1.4$ & $3.9 \pm 1.6$ & 0.32 & $4.4 \pm 1.8$ & $5.5 \pm 1.7$ & $0.00^{*}$ \\
\hline Humor & $2.9 \pm 1.2$ & $3.1 \pm 1.3$ & 0.22 & $2.7 \pm 0.9$ & $3.6 \pm 1.5$ & $0.00^{*}$ \\
\hline Emotional support & $4.1 \pm 1.7$ & $4.2 \pm 1.6$ & 0.40 & $4.6 \pm 2.1$ & $5.4 \pm 1.7$ & $0.00^{*}$ \\
\hline Acceptance & $5.2 \pm 1.3$ & $5.1 \pm 1.5$ & 0.34 & $5.5 \pm 1.6$ & $6.3 \pm 1.6$ & $0.00^{*}$ \\
\hline Self-distraction & $3.2 \pm 1.4$ & $3.4 \pm 1.6$ & 0.31 & $3.9 \pm 1.9$ & $5.5 \pm 1.7$ & $0.00^{*}$ \\
\hline \multicolumn{7}{|l|}{ C-Avoidant emotional } \\
\hline Behavioral disengagement & $4.7 \pm 1.4$ & $5 \pm 1.7$ & 0.06 & $5 \pm 1$ & $4 \pm 1.6$ & $0.00^{*}$ \\
\hline Substance use & $2.1 \pm 0.5$ & $2.1 \pm 0.5$ & 0.64 & $2.2 \pm 0.7$ & $2.1 \pm 0.4$ & 0.08 \\
\hline Self-blame & $4.3 \pm 1.9$ & $4.5 \pm 1.8$ & 0.32 & $5 \pm 2.1$ & $4.4 \pm 1.6$ & $0.00^{*}$ \\
\hline Denial & $3.9 \pm 1.7$ & $3.9 \pm 1.6$ & 0.79 & $3.5 \pm 1.7$ & $3 \pm 1.1$ & $0.00^{*}$ \\
\hline
\end{tabular}

Table 7 demonstrates that psychological distress was significantly negatively correlated with active coping $\left(r=-0.311^{*}\right)$, religion $\left(r=-0.359^{*}\right)$, and planning $\left(r=-0.264^{*}\right)$ positive reframing $\left(r=-0.269^{*}\right)$, humor $\left(r=-0.219^{*}\right)$ emotional support $\left(r=-0.221^{*}\right)$, acceptance $\left(r=-0.369^{*}\right)$, and self-distraction $(r=$ $\left.-0.458^{*}\right)$ and was significantly positively correlated with behavioral disengagement $\left(r=0.306^{*}\right)$ and substance use $\left(r=0.260^{*}\right)$ among the intervention group.

Table 6: Correlation between depression and coping strategies among intervention and control groups

\begin{tabular}{lll}
\hline Brief COPE & HRSD & \\
\cline { 2 - 3 } & Control & Intervention \\
\hline A-problem focused & $-0.197^{*}$ & $-0.573^{*}$ \\
Active coping & $-0.287^{*}$ & $-0.464^{*}$ \\
Religion & -0.095 & $-0.455^{*}$ \\
Planning & $-0.270^{*}$ & $-0.453^{*}$ \\
Instrumental support & 028 & $-0.351^{*}$ \\
B-Active emotional & -0.112 & $-0.384^{*}$ \\
Venting & 0.193 & -0.002 \\
Positive reframing & $-0.268^{*}$ & $-0.315^{*}$ \\
Humor & -0.118 & -0.164 \\
Emotional support & -0.037 & $-0.328^{*}$ \\
Acceptance & -0.118 & $-0.389^{*}$ \\
Self-distraction & $-0.292^{*}$ & $-0.436^{*}$ \\
C-Avoidant emotional & 0.081 & 0.153 \\
Behavioral disengagement & 0.035 & $0.340^{*}$ \\
Substance use & 0.012 & $0.216^{*}$ \\
Self-blame & $0.283^{*}$ & $0.302^{*}$ \\
Denial & $0.237^{*}$ & 0.119 \\
\hline HRSD: Hamilton Depression Rating Scale. & &
\end{tabular}

\section{Discussion}

Psychosocial developed health-care model leads to significant improvement on psychological health, mood, and coping of studied BC patients.

Among $185 \mathrm{BC}$ patients who participated in in the current study the mean age of the $\mathrm{BC}$ patients of control group was $48.7 \pm 13.2$ years and that of the intervention group was $47.9 \pm 11.9$ years. In a study done by Michael et al. including $128 \mathrm{BC}$ patients, mean age of control group was $49.31 \pm 8.33$ and that of the intervention group was $50.08 \pm 7.48$ and this age mean is nearly the same as our study [30].

Table 7: Correlation between psychological distress and coping strategies among intervention and control groups

\begin{tabular}{lll}
\hline Brief COPE & GHQ & \\
\cline { 2 - 3 } & Control & Intervention \\
\hline A-Problem focused & $-0.202^{*}$ & $-0.425^{*}$ \\
Active coping & -0.118 & $-0.311^{*}$ \\
Religion & -0.137 & $-0.359^{*}$ \\
Planning & $-0.347^{*}$ & $-0.264^{*}$ \\
Instrumental support & 0.016 & -0.211 \\
B-Active emotional & $-0.203^{*}$ & $-0.352^{*}$ \\
Venting & 0.173 & -0.157 \\
Positive reframing & $-0.240^{*}$ & $-0.269^{*}$ \\
Humor & 0.003 & $-0.219^{*}$ \\
Emotional support & -0.128 & $-0.221^{*}$ \\
Acceptance & $-0.333^{*}$ & $-0.369^{*}$ \\
Self-distraction & $-0.320^{*}$ & $-0.458^{*}$ \\
C-Avoidant emotional & -0.001 & -0.012 \\
Behavioral disengagement & 0.050 & $0.306^{*}$ \\
Substance use & 0.094 & $0.260^{*}$ \\
Self-blame & 0.159 & 0.134 \\
Denial & 0.136 & -0.064 \\
\hline GHQ: General health questionnaire. & &
\end{tabular}

Most of BC female patients in our study were married $(61.1 \%$ and $64.6 \%$ of control and intervention groups, respectively); that was in total agreement with Herranz et al. study that includes 107 patients in intervention arm and 81 patients in the control arm, conducted at Spain and reported that also most of the studied BC patients were married $(74 \%$ and $81.3 \%$ of control and intervention groups, respectively) [31].

As regard the percentage of high school and more in our results which represent $56.8 \%$ among control and $51.1 \%$ among intervention group; it truly reflects the pattern of education among Egyptians females as these results coincide with Egyptian demographic health survey (EDHS) 2014 results in which more than half of females have completed the secondary level or higher, reflecting the long-term trend toward increasing educational attainment among women in Egypt [32].

Our results showed nearly the same percentages as in Herranz et al. study, patients with preparatory or less education represent $45.6 \%$ and $44.8 \%$ of control and intervention groups respectively, high school or less represent $34.5 \%$ and $32.7 \%$ of control and intervention groups respectively, university represent 19.75 and $22.4 \%$ of control and intervention groups respectively [33].

Most of BC patients in this study are never employed represent $64.2 \%$ and $71.1 \%$ of control and 
intervention group, respectively; this is expected, as the $\mathrm{NCl}$ is a specialized free oncology treatment center for patients not covered with health insurance. This also could be explained as the whole sample was only females; this high percent goes with the EDHS 2014 results in which unemployment percent among females is $86.4 \%$ [34].

In the current study, there was statistical significant decrease in the mean of $\mathrm{GHQ}$ among intervention group from 7.9 (3.4) to 3 (4.5) with no statistical significant difference among control group which indicates improvement of the psychological distress among the intervention group.

The results were in agreement with Bray et al. study who conducted a longitudinal Randomized Controlled Trial (RCT) (home-based psychosocial intervention) at baseline (T1), after the 15-week intervention (T2), and 6 months later (T3) at 18 Australian sites, among 242 participants who were randomly assigned into intervention and control group, There was lower level of psychological distress using 12 items GHQ in the intervention group at T2 (21.78; $95 \% \mathrm{Cl}, 23.29$ to $20.27 ; \mathrm{p}=0.02$ ), with no significant difference at T3 $(21.50 ; 95 \% \mathrm{Cl}, 23.04$ to $0.04 ; \mathrm{p}=$ 0.06 ), no statistical significant difference among the control group [35].

Results of the current study showed that after intervention there was statistical significant decrease in the mean of HRSD from 12.5 (6) to 8 (6.8) this means that $\mathrm{BC}$ patients subjected to the intervention showed improvement in mood.

Our results were in agreement with Eichler et al. study where patients in the intervention group showed significant improvement of the depressive symptoms evidenced by HADS analysis with $57 \%$ reduction in patient depression levels [36].

Depression among BC patients was greatly reduced by the effect psychosocial intervention as reported by Barsevick et al. [37].

A meta-analysis done by Xiao et al. who assessed the effectiveness of individually delivered CBT interventions in improving depression in patients with $\mathrm{BC}$ using HRSD scale comparing the intervention groups to the control groups showed significant efficacy for individually delivered CBT in the reduction of depression with standardized mean difference $-2.61(95 \% \mathrm{Cl},-4.07$ to -1.14 ; overall effect $Z$, 3.49; $p=0.0005$ ) [38].

The current study revealed that among the control group there were no statistical significant changes except for instrumental support that was significantly decreased and venting mean that was significantly increased. As regarding follow-up of intervention group behavioral disengagement, selfblame and denial significantly decreased after 8 weeks of follow-up, while acceptance, self-distraction, emotional support, positive reframing, planning, humor, religion, and active coping increase significantly. There were no significant differences in instrumental support, substance use, and venting.

The current study revealed that among the control group, there were no statistical significant changes in the coping styles subscale except for active emotional coping style subscale that was significantly increased. This could be explained as women recover from the effects of treatment, they are generally able to return to their previous level of emotional functioning [39].

As regarding follow-up of intervention group means of the problem-focused, active emotional coping style subscales significantly increased after 8 weeks of follow-up (intervention group became more adaptive), while there were no significant differences in avoidant emotional coping style subscale.

A RCT, held in 2011 by Farajzadegan et al., showed that after the intervention, problem-focused coping strategies in the intervention group had significant improvement than the control group while emotion-focused strategies between the two groups were not significantly different [40].

This could be explained as coping strategies are sets of skills which are influenced by person's conditions, environment, culture and social support, insignificant emotion-focused strategies in Farajzadegan et al. study may be for this reason that trainings most affected the person and due to no change has happened in patient's living conditions and social support. Another reason may be that emotion-focused strategies need to increase the number of training sessions or have additional training.

Evidence showed that psychosocial interventions could help patients with cancer to cope better with stressful situations. This training leads to a more rapid return to normal life and lower limits at work and home [41]. Problem-focused strategies are associated with decreased anxiety, decreased depression and less psychological distress [42]. Belief that BC would have a chronic timeline is strongly related to the use of cognitive avoidance and behavioral avoidance coping strategies, with less use of problem-solving strategies [43].

As regard the correlation between different coping strategy and depression, our results showed that among the intervention and control group active coping, planning, positive reframing, self-distraction, and self-blame were significantly negatively correlated with depression. Elsheshtawy et al. study also found that there was significant positive correlation between anxiety and positive reframing $\left(r=0.298^{*}\right)$, planning $(r$ $\left.=0.277^{*}\right)$, and venting $\left(r=0.301^{*}\right)$ [28].

Our results showed that among the intervention group there was correlation between participants' use of religion $\left(r=-0.455^{*}\right)$, instrumental support $\left(r=-0.351^{*}\right)$, emotional support $\left(r=-0.328^{*}\right)$, acceptance $\left(r=-0.389^{*}\right.$, substance use $\left(r=-0.455^{*}\right)$, behavioral disengagement $\left(r=0.340^{*}\right)$, and their HADS depression scores. 
In our study, only denial $\left(r=0.237^{*}\right)$ was positively correlated with depression among the control group, BC patients used denial as a coping strategy, as it helped them to be distracted from the negative mood states [28].

\section{Limitation}

- $\quad$ Arranging time for the procedures of the study so as not to interfere with subjects' schedule (the rea)

- $\quad$ Facing uncooperative patients who did not have enough time and refused to join the study

- $\quad$ Limiting the study to the radiation oncology department in the $\mathrm{NCl}$ so results may not be generalized to all BC patients in Egypt.

\section{Conclusion}

Psychosocial developed health-care model leads to significant improvement on psychological health, mood and coping of studied BC patients, there was statistical significant decrease of psychological distress, social and emotional dysfunction and cognitive disorder, depression.

\section{Acknowledgment}

The authors acknowledge subjects for their participation and cooperation in this study.

\section{Authors' Contributions}

MIE: Research idea, data acquisition, data analysis, and interpretation, and manuscript writing and reviewing, ETE: Data acquisition, data analysis, and interpretation, THS: Performing and reviewing the research workup, SSM: Data acquisition, data analysis, and interpretation. All authors read and approved the final manuscript.

\section{References}

1. GBD 2017 Disease and Injury Incidence and Prevalence Collaborators. Global, regional, and national incidence, prevalence, and years lived with disability for 354 diseases and injuries for 195 countries and territories, 1990-2017. A systematic analysis for the global burden of disease study 2017. Lancet. 2018;392:1789-858. https://doi.org/10.341 0/f.731220250.793569875

\section{PMid:30496104}

2. Velikova-Tzonkova B. Perceived social support in cancer survivors: Some preliminary results. Psychol Thought. 2013;6(1):90-6. https://doi.org/10.5964/psyct.v6i1.64

3. American Society of Clinical Oncology. Depression and Anxiety 2012. Available from: http://www.cancer.net. [Last accessed on 2021 Jan 25].

4. Su JA, Yeh DC, Chang CC, Lin TC, Lai CH, Hu PY, et al Depression and family support in breast cancer patients. Neuropsychiatr Dis Treat. 2017;13:2389-96.

PMid:28979126

5. Borgi M, Collacchi B, Ortona E, Cirulli F. Stress and coping in women with breast cancer: Unravelling the mechanisms to improve resilience. Neurosci Biobehav Rev. 2020;119:406-21. https://doi.org/10.1016/j.neubiorev.2020.10.011

PMid:33086128

6. Voigt V, Neufeld F, Kaste J, Bühner M, Sckopke P, Wuerstlein R, et al. Clinically assessed posttraumatic stress in patients with breast cancer during the first year after diagnosis in the prospective, longitudinal, controlled COGNICARES study. Psychooncology. 2017;26(1):74-80. https://doi.org/10.1002/ pon.4102

PMid:26898732

7. Sami H, Hallaq E. Nonsuicidal self-injury among adolescents and young adults with prolonged exposure to violence: The effect of post-traumatic stress symptoms. Psychiatry Res. 2018;270:510-6. https://doi.org/10.1016/j.psychres.2018.10.028 PMid:30347378

8. Karakoyun-Celik O, Gorken I, Sahin S, Orcin E, Alanyali H, Kinay M. Depression and anxiety levels in woman under follow-up for breast cancer: Relationship to coping with cancer and quality of life. Med Oncol. 2010;27(1):108-13. https://doi.org/10.1007/ s12032-009-9181-4

PMid:19225913

9. Forcén FE, Jaramillo JR. The Darkness at the End of Life: Suicide in Palliative Care Settings. Suicide Prevention. Netherlands: Elsevier; 2018. https://doi.org/10.1007/978-3-319-74391-2_10

10. Bornbaum CC, Fung K, Franklin JH, Nichols A, Yoo J, Doyle PC. A descriptive analysis of the relationship between quality of life and distress in individuals with head and neck cancer. Support Care Cancer. 2012;20(9):2157-65. https://doi.org/10.1007/ s00520-011-1326-2

PMid:22124527

11. Lua PL, Salihah NZ, Mazlan N. Nutritional status and healthrelated quality of life of breast cancer patients on chemotherapy. Malays J Nutr. 2012;18(2):173-84.

PMid:24575665

12. Shields GS, Spahr CM, Slavich GM. Psychosocia interventions and immune system function: A systematic review and meta-analysis of randomized clinical trials. JAMA Psychiatry. 2020;77(10):1031-43. https://doi.org/10.1001/ jamapsychiatry.2020.0431 PMid:32492090

13. Gordon LG, Beesley VL, Scuffham PA. Evidence on the economic value of psychosocial interventions to alleviate anxiety and depression among cancer survivors: A systematic review. Asia Pac J Clin Oncol. 2011;7(2):96-105. https://doi. org/10.1111/j.1743-7563.2011.01395.x

PMid:21585688 
14. Fang CY, Reibel DK, Longacre ML, Rosenzweig $S$ Campbell DE, Douglas SD. Enhanced psychosocial well-being following participation in a mindfulness-based stress reduction program is associated with increased natural killer cell activity. J Altern Complement Med. 2010;16(5):531-8. https://doi. org/10.1089/acm.2009.0018 PMid:20455784

15. Faller $H$, Schuler M, Richard M, Heckl U, Weis J, Küffner R Effects of psycho-oncologic interventions on emotional distress and quality of life in adult patients with cancer: Systematic review and meta-analysis. J Clin Oncol. 2013;31(6):782-93. https://doi.org/10.1200/jco.2011.40.8922 PMid:23319686

16. Karademas EC, Simos P, Pat-Horenczyk R, Roziner L, Mazzocco K, Sousa B, et al. Cognitive, emotional, and behavior al mediators of the impact of coping self-efficacy on adaptation to breast cancer: An international prospective study. Psychooncology. 2021. https://doi.org/10.1002/pon.5730

17. Yilmaz SG, Arslan S. Effects of progressive relaxation exercises on anxiety and comfort of Turkish breast cancer patients receiving chemotherapy. Asian Pac J Cancer Prev. 2015;16(1):217-20. https://doi.org/10.7314/apjcp.2015.16.1.217 PMid:25640354

18. Mishra SI, Scherer RW, Snyder C, Geigle PM, Berlanstein DR, Topaloglu O. Exercise interventions on health-related quality of life for people with cancer during active treatment. Clin Otolaryngol. 2012;37(5):390-2. https://doi.org/10.1111/ coa.12015

\section{PMid:23164265}

19. Song $\mathrm{QH}, \mathrm{Xu} \mathrm{RM}$, Zhang $\mathrm{QH}$, Ma M, Zhao XP. Relaxation training during chemotherapy for breast cancer improves mental health and lessens adverse events. Int J Clin Exp Med. 2013;6(10):979.

PMid:24260607

20. Kashani F, Babaee S, Bahrami M, Valiani M. The effects of relaxation on reducing depression, anxiety and stress in women who underwent mastectomy for breast cancer. Iran J Nurs Midwifery Res. 2012;17(1):30.

\section{PMid:23493112}

21. Goldberg DP, Blackwell B. Psychiatric illness in general practice: A detailed study using a new method of case identification. $\mathrm{Br}$ Med J. 1970;2(5707):439-43. https://doi.org/10.1136/ bmj.2.5707.439

\section{PMid:5420206}

22. Goldberg D, Williams P. English, Book Edition: A User's Guide to the General Health Questionnaire. Windsor, Berks: NFERNelson; 1988. p. 129.

23. Daradkeh TK, Ghubash R, El-Rufaie OE. Reliability, validity, and factor structure of the Arabic version of the 12-item general health questionnaire. Psychol Rep. 2001;89(1):85-94. https:// doi.org/10.2466/pr0.2001.89.1.85

PMid:11729557

24. Hopko DR, Bell JL, Armento M, Robertson S, Mullane C, Wolf N, et al. Cognitive-behavior therapy for depressed cancer patients in a medical care setting. Behav Ther. 2008;39(2):126-36. https://doi.org/10.1016/j.beth.2007.05.007 PMid:18502246

25. Bachner YG. Psychometric properties of responses to an Arabic version of the hamilton depression rating scale (HAM-D6). J Am Psychiatr Nurses Assoc. 2016;22(1):27-30. https://doi. org/10.1177/1078390316629959

PMid:26929229

26. Panjwani AA, Revenson TA. Coping with chronic illness. In: The Wiley Encyclopedia of Health Psychology. United States: John Wiley and Sons Ltd.; 2020. p. 61-70. https://doi.

\section{org/10.1002/9781119057840.ch51}

27. Hagger MS, Koch S, Chatzisarantis NL, Orbell S. The common sense model of self-regulation: Meta-analysis and test of a process model. Psychol Bull. 2017;143(11):1117. https://doi. org/10.1037/bul0000118 PMid:28805401

28. Elsheshtawy EA, Abo-Elez WF, Ashour HS, Farouk O, Zaafarany MI. Coping strategies in Egyptian ladies with breast cancer. Breast Cancer. 2014;8:97-102. https://doi.org/10.4137/ bcbcr.s14755

29. García FE, Barraza-Peña CG, Wlodarczyk A, AlvearCarrasco M, Reyes-Reyes A. Psychometric properties of the Brief-COPE for the evaluation of coping strategies in the Chilean population. Psicologia. 2018;31:22.

30. Carayol M, Romieu G, Bleuse JP, Senesse P, GourgouBourgade S, Sari C, et al. Adapted physical activity and diet (APAD) during adjuvant breast cancer therapy: Design and implementation of a prospective randomized controlled trial. Contemp Clin Trials. 2013;36(2):531-43. https://doi.org/10.1016/j. cct.2013.09.016

PMid:24096188

31. Raingruber $B$. The effectiveness of psychosocial interventions with cancer patients: An integrative review of the literature (2006-2011). ISRN Nurs. 2011;2011:638218. https://doi. org/10.5402/2011/638218

PMid:22191052

32. Michael H, Lechner S, Diaz A, Vargas S, Holley $H$, Phillips K. Cognitive behavioral stress management effects on psychological and physiological adaptation in women undergoing treatment for breast cancer. Brain Behav Immunity. 2009;23(5):580-91. https://doi.org/10.1016/j.bbi.2008.09.005 PMid:18835434

33. Herranz JS, Manos D, Bueno MJ, Mateos N. Body image and self-esteem in women with breast cancer participating in a psychosocial intervention program. Psychol Spain. 2008;12:13-25.

34. Egypt Demographic and Health Survey (EDHS) Main Findings Ministry of Health and Population Cairo. Egypt El-Zanaty and Associates Cairo, Egypt The DHS Program ICF International Rockville. Maryland, USA: Egypt Demographic and Health Survey; 2014.

35. Bray VJ, Dhillon HM, Bell ML, Kabourakis M, Fiero MH, Yip D, et al. Evaluation of a web-based cognitive rehabilitation program in cancer survivors reporting cognitive symptoms after chemotherapy. J Clin Oncol. 2017;35(2):217-25. https://doi. org/10.1200/jco.2016.67.8201

PMid:28056205

36. Eichler C, Pia M, Sibylle M, Sauerwald A, Friedrich W, Warm M. Cognitive behavioral therapy in breast cancer patients--a feasibility study of an 8 week intervention for tumor associated fatigue treatment. Asian Pac J Cancer Prev. 2015;16(3):1063-7. https://doi.org/10.7314/apjcp.2015.16.3.1063 PMid:25735332

37. Barsevick AM, Sweeney C, Haney E, Chung E. A systematic qualitative analysis of psychoeducational interventions for depression in patients with cancer. Oncol Nurs Forum. 2002;29(1):73-84. https://doi.org/10.1188/02.onf.73-87 PMid:11817494

38. Xiao F, Song X, Chen Q, Dai Y, Xu R, Qiu C, et al. Effectiveness of psychological interventions on depression in patients after breast cancer surgery: A meta-analysis of randomized controlled trials. Clin Breast Cancer. 2017;17(3):171-9. https:// doi.org/10.1016/j.clbc.2016.11.003

PMid:28040415

39. Fawzy FI, Fawzy NW, Arndt LA, Pasnau RO. Critical review 
of psychosocial interventions in cancer care. Arch Gen Psychiatry. 1995;52(2):100-13. https://doi.org/10.1001/ archpsyc.1995.03950140018003

\section{PMid:7848046}

40. Farajzadegan Z, Khalili N, Mokarian F, Morovati AA. Coping skills improve quality of life in women with breast cancer and maladaptive coping Style. Soc Determin Health. 2015;1(1):18-29.

41. Koumarianou A, Symeonidi A, Kattamis A, Linardatou K, Chrousos G, Darviri C. A review of psychosocial interventions targeting families of children with cancer. Palliat Support Care. 2021;19(1):103-18. https://doi.org/10.1017/ s1478951520000449

PMid:32613930

42. Bussell VA, Naus MJ. A longitudinal investigation of coping and posttraumatic growth in breast cancer survivors. J Psychosoc Oncol. 2010;28(1):61-78. https://doi. org/10.1080/07347330903438958

PMid:20391066

43. Rozema $H$, Völlink $T$, Lechner $L$. The role of illness representations in coping and health of patients treated for breast cancer. Psychooncology. 2009;18(8):849-57. https://doi. org/10.1002/pon.1488

PMid:19085973 